\title{
Review Article \\ Emerging Roles of Focal Adhesion Kinase in Cancer
}

\author{
Yu-Ling Tai, ${ }^{1}$ Lih-Chyang Chen, ${ }^{2}$ and Tang-Long Shen ${ }^{1,3}$ \\ ${ }^{1}$ Department of Plant Pathology and Microbiology, National Taiwan University, Taipei 10617, Taiwan \\ ${ }^{2}$ Department of Medicine, Mackay Medical College, New Taipei City 25245, Taiwan \\ ${ }^{3}$ Center for Biotechnology, National Taiwan University, Taipei 10617, Taiwan \\ Correspondence should be addressed to Tang-Long Shen; shentl@ntu.edu.tw
}

Received 16 January 2015; Accepted 20 February 2015

Academic Editor: Hiroshi Hasegawa

Copyright (C) 2015 Yu-Ling Tai et al. This is an open access article distributed under the Creative Commons Attribution License, which permits unrestricted use, distribution, and reproduction in any medium, provided the original work is properly cited.

\begin{abstract}
Focal adhesion kinase (FAK) is a cytoplasmic nonreceptor tyrosine kinase that enables activation by growth factor receptors or integrins in various types of human cancers. The kinase-dependent and kinase-independent scaffolding functions of FAK modulate the authentic signaling and fundamental functions not only in cancer cells but also in tumor microenvironment to facilitate cancer progression and metastasis. The overexpression and activation of FAK are usually investigated in primary or metastatic cancers and correlated with the poor clinical outcome, highlighting FAK as a potential prognostic marker and anticancer target. Small molecule inhibitors targeting FAK kinase activity or FAK-scaffolding functions impair cancer development in preclinical or clinical trials. In this review, we give an overview for FAK signaling in cancer cells as well as tumor microenvironment that provides new strategies for the invention of cancer development and malignancy.
\end{abstract}

\section{Introduction}

Cancer signaling emanated from the interaction between cancer cells and tumor microenvironment is critical for cancer development. Integrins are essential bidirectional transmitters in regulating the physical link and signal communication between the inside and the outside of the plasma membrane. Upon integrins engagement with extracellular matrices (ECMs), integrins cluster together on the plasma membrane to ensure the efficient recruitment and activation of various molecules such as adaptor proteins (e.g., p130Cas and Crk), nonreceptor tyrosine kinase (i.e., Src family kinase and focal adhesion kinase), small GTPases (e.g., Rho, Rac, and $\mathrm{Cdc42}$ ), and cytoskeletal proteins (e.g., talin, vinculin, and paxillin) by forming intracellular specialized complexes and structures named as focal adhesions (or focal contacts) [1]. Utilizing varied signaling proteins within focal adhesions, integrin-mediated signaling enables transmitting cell adhesion signaling as well as tuning the reorganization of cytoskeleton, important for tumor progression, such as tumor angiogenesis and metastasis.

In response to cell adhesion, activation of focal adhesion kinase (FAK) is prominent followed by initially recruited to focal contacts and subsequently autophosphorylated on its Tyr397 to participate in integrin-mediated signaling and functions [2-4]. The FAK nonreceptor tyrosine kinase bears a central kinase domain flanked by an $\mathrm{N}$-terminal FERM (band 4.1 and ezrin/radixin/moesin homology domain) domain and a C-terminal region containing a FAT (focal adhesion targeting) domain and several proline-rich motifs [5], which allows transducing extracellular signals through tyrosine phosphorylation onto a diverse of intracellular molecules in the interior of a cell in both adhesion-dependent and growth factor dependent manners. Specifically, in line of integrin activation, the FAT domain of FAK enables targets FAK onto focal adhesion sites via interactions with other focal adhesion complex proteins, such as paxillin, vinculin, and talin. Consistent with this scenario, we have deciphered an inhibitory mechanism of FAK activation in which the intramolecular interaction between the FERM and kinase domains confers FAK toward an inactive conformation, and the release of this autoinhibition rendered by upstream integrin signaling (i.e., cell adhesion) and/or growth factor signaling in a proximal fashion allows the kinase domain of FAK accessible to numerous catalytic substrates essential for its activation and downstream signaling events [6-8]. Subsequently, 
the autophosphorylation of FAK on Tyr397 creates a highaffinity binding site for Src homology 2 (SH2) domain-containing proteins, such as Src family kinases, phosphoinositide 3-kinase, phospholipase $\mathrm{C}$, and growth factor receptor-bound protein 7 (Grb7) [9-12], thereby relying the upstream signal on versatile downstream signaling pathways. Moreover, the binding of Src family kinases onto the phospho-Tyr397 of FAK contributes to the promotion of FAK kinase activity and signaling as a result of additional tyrosine phosphorylations on several tyrosine sites, including Tyr407, Tyr576, Tyr577, and Tyr925 of FAK [5]. In fact, the phosphorylation of FAK on Tyr576 and Tyr577 by Src leads to a steric effect on preventing an intramolecular interaction between the aminoterminal FERM domain and the kinase domain within FAK [13]. On the other hand, phospho-Tyr925 of FAK provides a docking site for growth factor receptor-bound protein 2 (Grb2), leading to activation of a RAS-MEK/ERK cascade $[14,15]$. In addition, the scaffolding functionality of FAK through its phospho-tyrosine sites and two proline-rich motifs (mainly located within C-terminus) has been observed and elaborated in attribution with targeting a certain array of signaling proteins to focal adhesion sties in response to specific integrin activation [16]. Given the sophisticated regulated mechanism of FAK activation and signal transmission, a myriad of cellular and pathophysiological functions enable modulated in a coopted manner stemming from integrin and/or growth factor activation. Indeed, via recruiting and phosphorylating numerous signaling proteins, FAK empowers cell migration and modulates cell proliferation, adhesion, apoptosis, and differentiation in response to cell adhesion and mitogen stimulation $[5,17]$, implicating in controlling a wide range of processes of tumor [17]. Inevitably, the mechanistic nature of FAK activation and signaling has been intensively studied to highlight it as a potential target for anticancer therapeutics.

Tumor microenvironment, a mixture of varied cell types as well as secreted cytokines and deposited ECMs, is indispensable for tumor progression and metastasis [18, 19]. Upregulation of integrins and FAK is often observed to correlate with the progression of tumor development, implying the integrin/FAK signaling involved in regulation of tumor development [20]. Moreover, the activation of FAK enables modulation by growth factor stimulation. In this review, we provide an overview of FAK signaling in cancer cell biology and discuss how FAK signal transduction controls the cancer development and progression as summarized in Figure 1. In addition, we also summarize the potent anticancer drugs in relation to FAK-mediated signaling.

\section{FAK in Cancer Cells}

\subsection{FAK Signaling in Cancer Cell Survival and Proliferation}

2.1.1. FAK Regulates Cancer Survival. FAK-mediated signaling plays a critical role in the regulation of cancer cell survival. In opposite to cell adhesion, anoikis is a form of programmed cell death due to the disruption of cell-ECM interactions, in which FAK activity is lost and, therefore, results in cell apoptosis $[21,22]$. In contrast, often overexpression of FAK in cancer cells seems to attribute the resistance of cell detachment-induced cell death (i.e., anoiksis). Indeed, in these cancer cells, the increased FAK/Src complex confers the activation of both PI3K-AKT and MEK-extracellular signalregulated kinase 1/2 (ERK1/2) signal transductions, thereby enhancing the ability of cancer cell survival and growth in a cell detached condition [23]. In addition, several other upstream signals also contribute to FAK-mediated anoikis resistance in cancer cells. For example, transforming growth factor- $\beta$ (TGF- $\beta$ ) induces the activation of FAK and AKT via SMAD3 and p38 MAPK, respectively, which, in turn, results in anoikis resistance and tumor promotion [24]. In squamous cell carcinoma (SCC), fibronectin-mediated integrin $\alpha \mathrm{V}$ activation leading to FAK phosphorylation at Tyr397 prevents suspension-induced or tumor suppressor p53-mediated anoikis [25]. As expected, disruption of the organized fibronectin structure enables anoikis of SCC, presumably losing FAK phosphorylation and ERK activation. Moreover, overexpression of FAK has been shown to block the caspase-3-mediated apoptosis; conversely, inhibition of FAK leads to apoptosis in cancer cells [26]. Hence, knockdown of FAK expression by RNA interference promotes anoikis and further inhibits pancreatic cancer metastasis in vivo [27].

Antiapoptotic property is also essential for FAK in prevention of cancer programmed cell death. Actually, overexpression of FAK apparently links to the activation of PI3KAKT signal transduction and promotes the expression of NF$\kappa \mathrm{B}$-mediated inhibitor-of-apoptosis proteins (IAPs), which warrants apoptotic inhibition by blocking caspase- 3 cascade in human leukemia [28]. Likewise, the phosphorylation of $\mathrm{NF}-\kappa \mathrm{B}$ and activation of PI3K/AKT signaling modulated by FAK disable the tumor necrosis factor- $\alpha$ - (TNF- $\alpha$-) induced apoptosis [29]. Moreover, FAK also reportedly binds to the death domain kinase receptor-interacting protein (RIP), a component of death receptor complex in the programmed cell death, by which FAK is capable of suppressing apoptosis by blocking the function of death domain of RIP [30]. These studies indicate that an essential role for FAK activation and FAK-mediated signal transduction is to direct the fate of cancer cells by preventing the programmed cell death.

\subsubsection{FAK Regulates Cancer Proliferation. Cell proliferation} is a process of the increment of cell number as a result of cell division and growth. Discovery of the expression and tyrosine phosphorylation of FAK highly correlated with cell cycle progression by modulating cell cycle-relative molecules [31] highlights FAK functioning as a key regulator in promoting cancer proliferation. Eventually, overexpression of FAK enables increasing cyclin D1 expression and decreasing cyclin-dependent kinase (CDK) inhibitor p21 expression, thereby accelerating G1 to S-phase transition. Conversely, the competition of FAK localization and function out from focal contacts by a dominant-negative FAK mutant inhibits cell cycle progression at G1 phase [32]. Furthermore, FAK has been elaborated to modulate the E26 transformation-specific (ETS) binding site resided within the cyclin D1 promoter, which, in turn, regulates the transcriptional activation of 


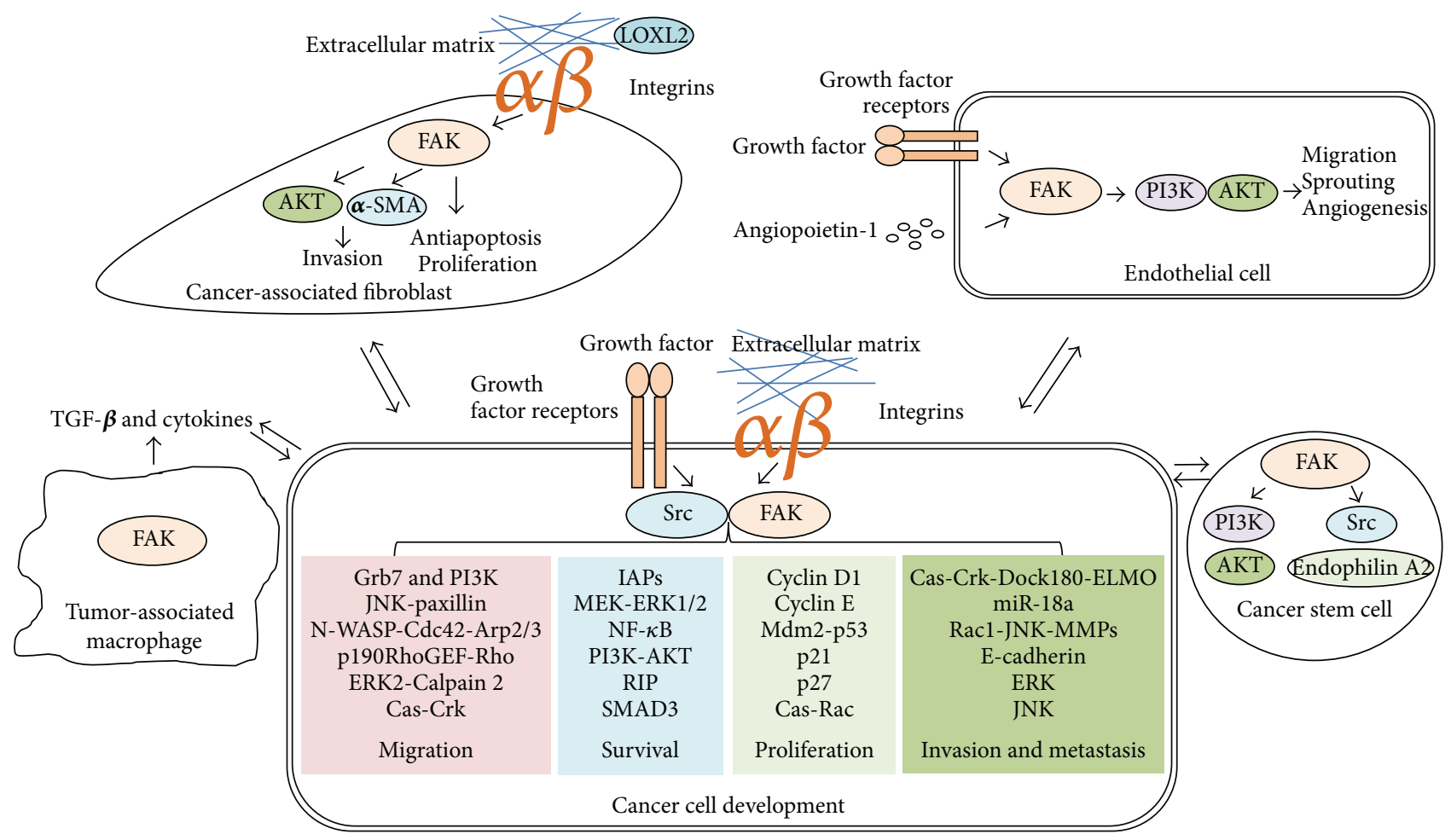

FIGURE 1: Model for FAK signal transduction in cancer cells and tumor microenvironment. The activation of FAK principally initiated by integrin engaged with ECMs and also by growth factor receptors enables regulating cell survival, proliferation, migration, invasion, and metastasis in relation to cancer development. Subsequently, the autophosphorylated (on Tyr397) FAK/Src complex empowers tyrosine phosphorylation cascades in modulating versatile signal pathways. For example, FAK modulates endophilin A2 phosphorylation by Src or PI3K-AKT signaling in cancer stem cells. In endothelial cells, vascular endothelial growth factor-A (VEGF-A)/VEGF or angiopoietin1 signalling regulates FAK-mediated PI3K/AKT activation to promote migration, sprouting, and angiogenesis. FAK also regulates the expression of growth factors or cytokines in tumor-associated macrophages to facilitate cancer progression. In response to LOXL2 stimulation, FAK affects the $\alpha$-SMA expression and AKT signaling to control invasion, antiapoptosis, and proliferation in cancer-associated fibroblasts.

cyclin D1 and leads to promoting cell cycle progression [33]. Indeed, overexpression of FAK also exits cell cycle from G1 phase in glioblastoma. Consistently, the promotion of cell cycle progression by FAK is mediated by enhanced expression of cyclin D1 and cyclin E in concert with reduced expression of CDK inhibitors p $27^{\text {Kip1 }}$ and p $21^{\text {Waf1 }}$ [34].

The tumor suppressor p53 triggers lots of antiproliferative processes, such as DNA repair, apoptosis, and cell cycle arrest [35]. On the other hand, FAK promotes cell cycle progression by the blockage of tumor suppressor p53-mediated apoptosis and the inhibition of p53 transcriptional activity [36]. Mechanically, it has been proposed that FAK might exert its FERM domain as a scaffold to stabilize p53 and ubiquitin E3-ligases Mdm2 in the nucleus, which, in turn, enhances Mdm2-dependent p53 ubiquitination and subsequently leads to $\mathrm{p} 53$ polyubiquitination and degradation. In other words, the nuclear FAK's FERM domain enables mediating p53 turnover in regulation of cell proliferation and survival [37]. Accordingly, mammary tumor malignancy and progression originated from the loss of $\mathrm{p} 53$ expression or overexpression of a dominant-negative $\mathrm{p} 53^{\mathrm{R} 270 \mathrm{H}}$ mutant are impeded upon FAK deletion [38]. Thus, FAK modulates cancer cell proliferation by either regulating cell cycle-relative molecules or promoting tumor suppressor turnover.

\subsection{FAK Signaling in Cancer Cell Migration, Invasion, and Metastasis}

2.2.1. FAK Signaling-Mediated Cytoskeleton Remodelling in Cell Migration. Cytoskeletal remodelling is critical for cancer cell migration, therefore indispensable for cancer metastasis. FAK signaling which resulted from ECM-induced integrin clustering intimately involves in the reorganization of cytoskeleton and cell motility. In response to specific chemoattractant signals, such as ECMs and growth factors, protrusions are formed at the leading edge by polymerization of actin filaments towards the cell plasma membrane, following the formation of focal adhesion complexes where activated integrins render the recruitment and activation of FAK $[39,40]$. Through the FAK/Src complex formation and kinase activity, cell migration is profoundly affected by the subsequent phosphorylated p130Cas in promoting the formation of Cas/Crk complex [41], myosin light-chain kinase- (MLCK-) mediated focal adhesion disassembly [42], c-Jun N-terminal kinase- (JNK-) mediated phosphorylation of paxillin in facilitating cytoskeleton reorganization [43], interactions with PI3-kinase and/or Grb7 in governing intracellular signaling related to cell motility [44, 45], and so on. Beside the essential role for the focal adhesions 
assembly, integrin-mediated FAK signaling governs focal adhesion turnover (adhesion dynamic) to ensure a dynamic and complex process of the membrane protrusion during cell migration. For example, enhanced extracellular signalregulated kinase 2 (ERK2) activity mediated by the formation of the FAK/Src complex at focal adhesion sites leads to protease Calpain 2 activation, which subsequently allows Calpain 2 to cleave the molecules, for example, FAK and talin, at the focal adhesion sites in facilitating focal adhesion turnover in motile cells [46-48].

FAK also impacts on the remodelling of actin cytoskeleton and stabilization of focal adhesions through its effect on small GTPases [17]. Small GTPases (i.e., RhoA, Racl, and Cdc42) function as critical roles in cytoskeleton reorganization [49]. RhoA affects cell-cell or cell-ECMs interaction by inducing the change of cytoskeleton, Racl plays a role in membrane ruffling via driving actin polymerization, and Cdc42 involves in the formation of filopodia through initiating actin filament assembly [49-51]. Given to bearing GAP activity for RhoA and Cdc42 [52], Graf, a FAK interacting protein, empowers FAK signaling in regulation of actin cytoskeleton reorganization. Alternatively, the formation of the FAK/N-WASP complex leads to the activation of Cdc42, followed by engagement of Arp $2 / 3$ and actin filament formation [53, 54]. Moreover, FAK binds to p190RhoGEF which leads to the activation of Rho and maturation of focal adhesions in association with tumor migration [54]. These studies provide evidence for FAK and its signaling in substantially controlling Rho GTPases and subsequently vital for cytoskeletal reorganization.

\subsubsection{FAK Promotes Cancer Invasion. Cancer invasion} toward the surroundings at the primary site is a critical event for tumor malignancy. Numerous numbers of evidence indicate that FAK predominately involves in the promotion of tumor invasion, implicating that FAK is a potential target for anticancer therapeutics. In a coopted manner of receptor tyrosine kinase and integrins, the formation of the FAK/Src complex reinforces FAK signaling through p130Cas to recruit the Crk-Dock180-ELMO complex in promoting the activation of Racl, which, in turn, activates JNK protein and results in MMPs production for ECM proteolysis [17, 55]. The consequence of MMP-mediated ECM proteolysis is pivotal for cancer invasion that can be facilitated by FAK-mediated signaling in response to mobile signals. Nevertheless, prior to cell invasion, cancer cells per se need to proceed with a developmental and morphological alternation called epithelialmesenchymal transition (EMT), a process to transdifferentiate epithelial cells into motile mesenchymal cells [56]. Epithelial cadherin (E-cadherin) is the major molecule resided within epithelial adherent junctions. During the occurrence of EMT, degradation of E-cadherin is accordant with the disruption of adherent junctions, which allows the release of cell-cell restriction and, therefore, promotes cancer invasion [49]. Reportedly, the phosphorylation of FAK at Tyr407 and Tyr861 by the FAK/Src complex drives the interruption of E-cadherin-mediated epithelial adherent junctions [5759]. Consistently, transforming growth factor- $\beta$ - (TGF- $\beta$-) induced EMT because of downregulation of E-cadherin is mediated by the activation of FAK in a Src dependent manner [60]. In the process of cancer invasion, the activation of FAK in cancer cells could transmit numerous downstream signal pathways in regulating a variety of cellular events, including cytoskeletal remodelling and EMT, to control cell fate.

\subsubsection{FAK Promotes Cancer Metastasis. In agreement with} its essential role in cell migration, FAK is inferred to be crucially involved in cancer metastasis due to the fact that overexpression and activation of FAK are often clinically associated with cancer metastasis [54, 61, 62]. Actually, the Tyr397 phosphorylation and kinase activity of FAK are substantiated to be important for the invasive phenotype as well as cancer metastasis [63]. Intrinsically, FAK kinase activity has been emphasized in the promotion of cancer metastasis by regulating the expression of MMP9 and urokinase plasminogen activator [64]. In addition, increased FAK expression can rescue the miR-7 negative effect on tumor migration and invasion [65]. Accordingly, suppression of FAK expression and signaling by RNA interference (RNAi) or dominant-negative mutants of FAK (i.e., FAKrelated nonkinase, FRNK) generally enables inhibiting FAKtriggered cancer metastasis [66-69]. The fact is that FRNK expression reducing the FAK phosphorylation on Tyr397 and decreasing the formation of focal adhesions is attributed to its inhibitory effect on cancer metastasis in vivo, rather than the FRNK-induced dormancy or apoptosis of cancer cells [70]. Moreover, FRNK expression also disrupts the formation of $\mathrm{v}$-Src/FAK complex, which, in turn, inhibits p130Cas activity and reduces the v-Src-stimulated ERK and JNK kinase activation, leading to impair v-Src-mediated cell invasion and metastasis [71]. On the other hand, using RNAi targeting FAK to reduce the expression of FAK has been observed in reduction of cancer metastasis in cervical lymph node metastasis of tongue cancer [66]. Additionally, although a synergistic effect of FAK and epidermal growth factor receptor (EGFR) is highlighted for their cooperation in the promotion of non-small cell lung cancer metastasis, knockdown of FAK and EGFR expression using short hairpin RNA (shRNA) significantly inhibits cancer metastasis [72]. These observations emphasize the important role for FAK in regulating tumor malignancy by directing cancer invasion and metastasis.

2.3. FAK in Cancer Stem Cells. In spite of being controversial, cancer stem cells remain an attractive subject for understanding underlying tumorigenesis and malignancy as well as cancer therapeutics. As defined, cancer stem cells bear the ability to self-renewal, differentiate into versatile cancer cell types, and promote tumor progression [73]. Additional property in maintaining a relatively quiescent and long life span renders cancer stem cells more resistant to current chemotherapies [74]. Recently, deletion of FAK in mammary epithelial cells (MaECs) has been reported to affect breast cancer development, that is, suppression of mammary tumor formation and progression, in the mammary tumor mouse MMTV-PyMV model [75]. In that study, impairment of the 
cancer stem cell maintenance in FAK ablated MaECs has been taken into account for the decreased tumorigenicity and metastasis of mammary tumors [75]. Indeed, loss of FAK leads to less activation of the PI3K-AKT signaling and, therefore, impedes MaCSC self-renewal and tumorigenicity [76] although a compensatory activity by Pyk2, a nonreceptor tyrosine kinase of the FAK family, might appear [76]. Besides, the role of integrin/FAK signaling in the regulation of cancer stem cells is observed in squamous cell carcinomas [77]. Yet, these studies remain unidentifying the mechanistic nature of FAK and its signaling involved in regulation of cancer stem/progenitor cell population. In this regard, the differential role of kinase-dependent and kinase-independent functions of FAK in mammary stem cells (MaSCs) and luminal progenitors had been explored. The kinase activity is required for the sphere-forming of MaECs and the proliferation of luminal progenitor; in contrast, the kinaseindependent function of FAK necessitates in ductal invasion and basal MaSC activity [78]. Consequently, the inhibitor of FAK kinase activity is not efficient in targeting MaSC-like human breast cancer cells compared with luminal progenitorlike basal breast cancer cells [78]. Furthermore, a functional defect of FAK on its Pro-878/881 motifleads to impairing FAK scaffolding in mediating endophilin A2 phosphorylation by Src, thereby leading to profound decreases in epithelialmesenchymal transition (EMT) and MaCSC activities [79]. Collectively, these findings provide an intrinsic role for FAK in the regulation of cancer stem cells, which entails FAK as a novel target for anticancer therapeutics by intervention of the cancer stem cell activity.

\section{FAK in Tumor Microenvironment}

During cancer progression and malignancy, tumor cells continuously encounter with their surroundings in a dynamic and complicated manner. Nevertheless, tumor microenvironment commonly indicates the solid-state extracellular matrices (ECMs), resided soluble factors, nonneoplastic cells, including cancer-associated fibroblasts, endothelial cells, bone marrow progenitor cells, and tumor-associated macrophages, and so on [18]. The communication between cancer cells and tumor microenvironment is mainly attributed by secreted soluble factors (e.g., growth factors, cytokines, and chemokines) and extracellular matrices remodeling enzymes (e.g., matrix metalloproteinases, MMPs and tissue inhibitor of metalloproteinases, and TIMPs) governing cellcell and cell-EMC interactions as well as cell signaling events [80].

Tumor microenvironment is an essential and vital niche in support for the developmental process of tumors. As mentioned above, in light of tumor microenvironmental cues, activation of FAK is capable of driving the integrinand growth factor receptor-mediated signaling inside of a cell to ignite tyrosine phosphorylation cascades and reorganize cytoskeleton of tumor cells. On the other hand, how the FAK of tumor-associated cells resided within the tumor microenvironment activated and contributing to tumor progression is exploring in recent years. Herein, the emerging roles of FAK in the varied cell types of tumor microenvironments will be discussed below.

3.1. Integrins/FAK Signaling in Response to ECMs in Tumor Microenvironment. Cumulative deposition and remodeling of ECMs fabricating a stiffer tumor microenvironment usually result in resided tumor cells losing the regular cytoskeletal organization [81]. As cell adhesion receptors, integrins possess specific and varied binding affinities with various ECM molecule compositions to provide a tensional homeostasis in response to the tense states of tumor microenvironments. Authentically, the mechanotransduction caused by the ECM stiffness enables reflecting on integrin-mediated FAK signaling influences tumor progression [82]. Increased lysyl oxidase (LOX) activity has been highlighted responsible for the consequence of ECM stiffness due to its ability for collagen cross-link, which is in accordance with the promotion of cancer malignancy as well as invasiveness and metastasis in varied cancers, including breast cancer cells [83], brain tumor [84], and colorectal cancer progression [85]. In response to the increment of tumor matrix-stiffness, activation of FAK is also correlated with the clustering of $\beta 1$ integrin encountering with the stiffen matrices and then elicits PI3K/AKT signaling [86]. In addition, ECM stiffness initiated by LOX activation is also capable of activating MYCinduced upregulation of miR-18a in need of $\beta 1$ integrin clustering. Thus, reduction of FAK activity by a FAK inhibitor is proved to modulate the expression of miR-18a followed by lowing PTEN expression and elevating PI3K/AKT signaling in promoting tumor invasion and metastasis [87]. Moreover, the activation of FAK through ECM stiffness can modulate the intracellular structure and promote cell cycle progression rather than cell migration [88], in which the FAK/p130Cas/Rac signaling pathway is responsible for Sphase entry in the aid of increased cyclin D1 [88]. ECM stiffness-mediated FAK activation and FAK-regulated tumor biological functions in distinct malignant cancers suggest that the ECM-mediated FAK signal transduction might function as a general and crucial point in tumor developmental processes.

3.2. Endothelial Cell FAK Contributes to Tumor Angiogenesis. In addition to tumor cells, FAK also plays an essential role in endothelial cells involved in tumor progression. Tumor angiogenesis as a process for the formation of new blood vessels is an essential step for the development of tumor malignancy. Indeed, FAK signaling is important to regulate angiogenesis in embryonic development as well as pathological angiogenesis (e.g., tumor angiogenesis) [8992]. The expression and activation of FAK are frequently correlated with endothelial cell survival, proliferation, and migration [93, 94]. For example, VEGF-A/VEGF-receptor 2 signaling induces the FAK/PI3K complex formation by which endothelial cells migration is promoted to facilitate angiogenesis [95]. In addition, FAK phosphorylation mediated by angiopoietin-1 stimulation also enhances endothelial cell sprouting in a PI3K dependent manner [96]. Moreover, FAK-deleted endothelial cells reduce tumor angiogenesis, 
which is caused by reduction of VEGF-mediated AKT phosphorylation [89]. In tumor-associated endothelial cells, FAK activity is essential for VEGF-mediated tumor extravasation and metastasis [97]. Collectively, FAK contributes to tumor development in diverse mechanisms. Realization of FAKmediated signaling highlights and provides the opportunities in the development of anticancer therapeutics.

3.3. FAK in Tumor-Associated Macrophages. Tumour-associated macrophages (TAMs) play a protumoral role via stimulation of angiogenesis and enhancement of tumor cell invasion, migration, and metastasis. TAMs are also immunosuppressive, preventing tumor cell attack by $\mathrm{T}$ cells and NK cells during tumor progression and after recovery from chemotherapy or radiotherapy [98]. FAK signaling is required for macrophage motility induced by integrin engagement [99]. Importantly, inhibition of FAK signaling reduces the infiltration of macrophages into tumor tissues [100-102]. FAK in TAMs is thought to be bioactive; however, how FAK in TAMs regulates TAMs-mediated tumor malignancy is largely unknown. Nevertheless, the followings indicate a potential protumoral role of FAK in TAMs.

TAMs promote tumor growth and distant metastasis by secretion of various kinds of proteins in the paracrine manners that induce tumor epithelial-mesenchymal transition, invasion, migration, and angiogenesis [98]. It is worth to note that the effect of FAK in TAMs on the expression of these proteins. Epithelial-mesenchymal transition is induced in the invading tumor cells by TGF- $\beta$ that is expressed by TAMs and is regulated by FAK in fibroblast cells $[98,103]$. The process of tumor migration requires matrix remodeling facilitated by matrix metalloproteinase 9 that is regulated by FAK in follicular thyroid carcinoma cells and fibroblasts [104-106]. In addition, neovascularization is important to tumor growth and metastasis. TAMs stimulate neovascularization by the production of VEGF and IL-8 $[98,107]$. The expression of VEGF is regulated by FAK in epithelial cells [108, 109] as well as the expression of IL-8 in fibroblast-like synoviocytes and epithelial cells $[110,111]$. In addition to establishment of a favorable microenvironment, TAMs also inhibit the antitumor immune responses through the suppression of cytotoxic functions and the induction of apoptosis in T cells and NK cells. Therefore TAMs attenuate tumor surveillance in the tumor progression and antitumor immunity elicited by tumor-derived antigens released from therapy-mediated dying tumor cells [112]. TGF- $\beta$ expressed by TAMs is regulated by FAK in fibroblast cells and can inhibit $\mathrm{T}$ cells effector functions through the induction of regulatory $\mathrm{T}$ cells $[98,103]$. Taken together, FAK is important to the induction of TAMs through the recruitment of macrophages into tumor tissues and potentially execute protumoral functions through the ability to regulate the downstream gene expression. The potential role of FAK in TAMs is largely unknown and worth to be investigated.

3.4. FAK in Cancer-Associated Fibroblast. Cancer-associated fibroblasts (CAFs) within tumor stroma promote cancer development by secreting chemokines or growth factors to govern several oncogenic signals in cancer cells, endothelial cells, and inflammatory cells $[113,114]$. FAK had been reported to involve in the regulation of CAFs. Tumor-derived lysyl oxidase-like 2 (LOXL2) promotes the expression of $\alpha$-smooth muscle actin ( $\alpha$-SMA) and activates fibroblasts through integrin-mediated FAK activation and AKT signaling [115]. Moreover, inhibition of FAK leads to impairing the phosphorylation of AKT as well as the reduction of the expression of $\alpha$-SMA [115]. FAK activation is also important to prevent the anoikis by providing the antiapoptotic signal in both fibroblasts and epithelial cells, which implies that FAKmediated aberrant survival signals in normal cells might play some functions in affecting the cancer development [116]. On the other hand, $\mathrm{FAK}^{-/-}$fibroblasts block cell migration; the reexpression of FAK and the kinase activity of FAK in $\mathrm{FAK}^{-/-}$fibroblasts are required for cell migration and invasive phenotype defects [63]. Indeed, loss of FAK in the epidermis had been reported to reduce the malignant progression of skin cancers by enhancing the apoptosis [117]. In addition, the activation of FAK might alter the organization of tumor microenvironment and facilitate the cancer development in pancreatic ductal adenocarcinoma (PDA) [100]. In PDA mouse model, inhibition of FAK impairs cancer cells proliferation and leads to the decreased CAFs recruitment [100]. Based on the study about the prognostic gene-expression signature of CAFs in non-small cell lung cancer, the modulation of focal adhesion signaling might be regulated by integrin and FAK signal transductions [118]. These studies suggest that FAK is vital in the cancer development by regulating the cellular and biological functions of CAFs.

\section{FAK in the Development of Targeted Therapeutics}

Overexpression of FAK has been clinically observed in primary human sarcomas [119], human prostate carcinomas [120], human ovary carcinomas [121], human colorectal carcinomas [122], and breast cancers [123], implicating the role of FAK in cancer development. Experimental evidence also indicates that FAK-mediated signaling and functions intrinsically involve in the development of tumor malignancy, suggesting that FAK is a promising target for anticancer therapies. Eventually, several approaches have been developed to modulate the expression or activation of FAK, including small chemical inhibitors, PF-573,228 and VS-4718, in capable of blocking the autophosphorylation of FAK on Tyr397. According to the aforementioned roles for FAK in cancer, some inhibitors have been launched in phase I clinical trial for anticancer therapies. Besides, targeting specific proteinprotein interaction which prevents the transduction of FAKmediated signaling is an alternative strategy for anticancer therapy. The following will further summarize and discuss recent development and progression of FAK-related anticancer therapies.

4.1. FAK in Human Cancers. Several mechanisms have been reasoned for the overexpression of FAK protein in human 
cancer in correlation with the fak gene amplification. Using in situ hybridization, increased dosage of the fak gene on chromosome $8 \mathrm{q} 24.3$ is invariantly observed in the cell lines derived from human cancers of lung, breast, and colon [124]. Moreover, gains in copy number of fak gene in invasive squamous cell carcinomas also revealed in correlation with elevation of FAK protein and tumorigenesis [124]. In addition, both primary colorectal cancers and colorectal liver metastases express high levels of FAK mRNA copy number as well as FAK protein expression level [122]. However, elevated FAK expression is not always correlated with gains on fak gene amplification. For example, in human head and neck squamous cell carcinoma, not all cases with an amplification of the fak gene displayed FAK protein overexpression [125], implicating a sophisticated posttranscriptional regulation involved in FAK expression and functions.

By analyzing the $5^{\prime}$ promoter region of the fak gene, NF$\kappa \mathrm{B}$ and $\mathrm{p} 53$ transcription factors can bind within the FAK promoter region [126]. However, NF- $\kappa \mathrm{B}$ and p53 transcription factors exhibit opposite activities in the regulation of FAK transcription. NF- $\kappa \mathrm{B}$ induces FAK transcription, whereas p53 suppresses FAK transcriptional activity [126]. In human breast and colon cancers, FAK expression is significantly increased in tumors containing p53 mutations in comparison to tumors bearing wild-type p53 [127, 128]. Moreover, missense p53 mutations in its DNA-binding domain, that is, V173M, R249M, and R282M, also confer to promote the FAK promoter activity [127]. Furthermore, miR-151 derived from the intron 22 of the fak gene which is often coexpressed with its host gene fak may also be regulated by p53 transcription factor in human hepatocellular carcinoma [129]. The synergistic effect of miR-151 and FAK can stimulate Rac1, Cdc42, and Rho GTPases signaling, which, in turn, leads to enhancing cancer motility and invasion [129]. These studies imply that FAK expression and its biological functions may be modulated by the transcriptional regulators and its coamplification miR-151.

The upregulation of FAK has been specifically associated with liver metastases of colon cancer, which infers a role for FAK in tumor invasiveness in vivo [130]. Several studies suggest that a coordinate modulation of FAK-mediated signals and functions is crucial for tumor malignancy [131-133]. Moreover, the overexpression of FAK and phosphorylation of FAK on Tyr397 is frequently associated with tumor metastasis as well as poor patient prognosis [134-136], indicating a critical role for FAK in tumor progression and malignancy. These studies suggest that FAK could be functioned as a potential prognostic marker and anticancer candidate.

4.2. Targeting Kinase Activity of FAK. In agreement with the importance of FAK kinase activity in FAK-mediated signaling and development of tumor malignancy, ATP-competitive kinase inhibitors are capable of binding the ATP-binding pocket of FAK to efficiently block FAK catalytic activity. Their potency, signaling effect, and functional efficacy on tumor malignancies will be discussed as follows.

PF-573,228. This compound is a bisamino pyrimidine derivative with the half maximal inhibitory concentration $\left(\mathrm{IC}_{50}\right)$ for the FAK catalytic activity at $4 \mathrm{nM}$ whereas for FAK autophosphorylation on Tyr397 at 30-100 nM. Importantly, PF-573,228 blocks cell migration in concomitant reduction in the disassembly of focal adhesions. In contrast, this compound fails to inhibit cell growth or induce cell apoptosis [137].

TAE226. This compound is a bisanilino pyrimidine derivative. TAE226 inhibits the phosphorylation of FAK and the FAK-mediated signaling, such as AKT, ERK, and S6 ribosomal protein in glioma [138]. Subsequently, the inhibition of FAK signaling by TAE226 induces the cell cycle arrest and increases cancer apoptosis. TAE226 also impairs glioma tumor adhesion, migration, and invasion [138]. Besides glioblastomas, TAE226 is capable of accomplishing the detachment and apoptosis of breast cancers but no effects on MCF-10A normal breast epithelial cells [139]. In animal models, TAE226 prolongs the survival rate with breast cancer bone metastasis [140]. TAE226 also suppresses the growth and angiogenesis of oral squamous cell carcinoma in a xenograft mouse model [141]. To be noted, in addition to FAK kinase activity, this compound also blocks the activation of poly (ADP-ribose) polymerase and caspase-3. [139]. Currently, TAE226 has been undergone its efficacy test in the preclinical phase.

PND-1186 (Also Termed VS-4718). This compound is a substituted pyridine reversible inhibitor for FAK activity with an $\mathrm{IC}_{50}$ at $1.5 \mathrm{nM}$ in vitro [142]. Not only reduction in cell migration but also PND-1186 triggers cancer apoptosis in a $3 \mathrm{D}$ environment via blockage of the FAK/p130Cas tyrosine phosphorylation cascade and induction of caspase-3 activation [142]. Consistently, PND-1186 impacts on oncogenic KRAS- and BRAF-stimulated MDA-MB-231 breast cancer growth and metastasis by blocking FAK and p130Cas phosphorylation [143]. In the preclinical phase, PND-1186 displays anticancer efficacy in orthotropic breast cancer mouse models. At present, PND-1186 is under phase I clinical trial.

PF-562,271 (Also Termed VS-6062). This compound is a bisamino pyrimidine derivative as a FAK activity inhibitor with an $\mathrm{IC}_{50}$ at $1.5 \mathrm{nmol} / \mathrm{L}$ [144]. In therapies for pancreatic ductal adenocarcinoma model, PF-562,271 inhibits migration of cancer cells, cancer-associated fibroblasts (CAFs), and tumor-associated macrophages (TAMs) [100], indicating that PF-562,271 may exert a novel mechanism in inhibiting cancer metastasis by altering the tumor microenvironment. PF562,271 has been on the progress of the clinical trial targeting advanced solid tumors [145].

\subsection{Alternative Mechanism to Block FAK-Mediated Cellular} Functions. Protein-protein interactions are a fundamental event for signal transductions and involved in the development of tumor malignancy. Eventually, recruitment and interaction with the intracellular domain of growth factor receptors (e.g., insulin-like growth factor receptor-1, IGF-1R and vascular endothelial growth factor 3, VEGFR-3) are required for FAK activation essential for regulations of diverse signal transductions in relation to cancer development. These 
observations prompt a possibility to interrupt the interaction between FAK and growth factor receptors for potential anticancer therapeutics. For example, a small molecular compound chloropyramine hydrochloride (called C4) targets the interaction between FAK and VEGFR-3, which, in turn, reduces the phosphorylation of both proteins, leading to decreasing the proliferation and causing the apoptosis in breast cancer [146]. Besides, a compound INT2-31 targets the FAK/IGF-1R complex and further effectively inhibits AKT phosphorylation, leading to decreasing melanoma cells proliferation and tumor growth in vivo [147]. Furthermore, rather than disruption with growth factor receptors, the $5^{\prime}-O$ tritylthymidine (called M13) compound blocks the formation of the FAK/Mdm-2 complex; subsequently, it activates p53 and caspase-8, leading to increase detachment and apoptosis in breast and colon cancers [148]. Likewise, a small molecule compound R2 can disrupt the interaction between FAK and p53, which, in turn, increases p53 transcriptional activity, contributing to inhibit tumor growth [149]. These compounds target FAK scaffold which is a critical strategy to block the FAK-mediated cancer development.

Alternatively, RNA interference (RNAi) is an emerging means for anticancer therapies. Using RNAi to inhibit FAK expression, it can lead to the death of anoikis-resistant tumor cells and also reduce the metastasis of pancreatic cancer in a mouse model [27]. Simultaneous inhibition of both FAK and EGFR expression by specific shRNAs exhibits a synergistic effect on lung cancer metastasis in vivo [72]. In addition, ectopic expressions of miR-138 and miR-135 targeting the FAK $3^{\prime}$ UTR reportedly suppress FAK-mediated tumor growth and invasion as well as drug sensitivity [150]. miR-7 also serving as a direct regulator of FAK expression by targeting the FAK $3^{\prime}$ UTR, as expected, enables suppressing the FAK-mediated malignancies in aggressive breast cancers, such as proliferation, anchorage independent growth, migration, and invasion [65]. Besides, the dominant-negative mutants of FAK (i.e., FAK-related nonkinase, FRNK) may also provide an alternative way to block FAK-triggered cancer malignancy [66-69]. These strategies via targeting FAK mRNA or FAK-mediated protein-protein interaction/signal transduction advance the development of FAK-targeted therapeutics.

\section{Conclusions}

The kinase-dependent function and kinase-independent scaffolding ability of FAK are equivocally essential for cancer development. Moreover, the multifunctional characteristics of FAK have been highlighted to modulate numerous signal transductions in governing the activities and functions of the tumor microenvironment, cancer cells, and/or cancer stem cells (Figure 1). However, the complicated cross talk and regulatory loops modulated by FAK between the tumor microenvironment and cancer cells/cancer stem cells remain to be deciphered. In lines of clinical observations, overexpression of FAK at both transcriptional and translational levels in human varied cancers implies that FAK could be a prognostic marker and a potential anticancer candidate for target therapies. In fact, several small compounds targeting the catalytic activity, protein-protein interactions, and even RNAi of FAK have been launched for conducting clinical trials and some clarifications remain to be verified such as drug sensitivity for specific types or stages of cancers, appropriate dosages, side effects, and the toxicity [151]. Beyond this, the resistance of cancers to FAK inhibitor should be pondered deeply as the next problem. Several studies indicate that the combination of FAK inhibitor with chemotherapy or other anticancer molecules as a combinatory therapy for cancers effectively attenuates cancer development [146, 152]. Nevertheless, the synergistic effect of the combination of FAK inhibitor and chemotherapy or other anticancer molecules remains to be investigated for its possible regulatory mechanisms in the anticancer therapy. Collectively, the profound progress during the past decades in the molecular and cellular mechanisms and cancer biology of FAK has provided much basic and clinical medical knowledge for targeting FAK as a potential anticancer therapeutic strategy.

\section{Conflict of Interests}

The authors declare that there is no conflict of interests regarding the publication of this paper.

\section{Acknowledgments}

This work was supported by Frontier Research Grant from National Taiwan University (103R78221 to T.-L. Shen) and Ministry of Science and Technology, Taiwan (103-2320-B002-046 to T.-L. Shen).

\section{References}

[1] R. O. Hynes, "Integrins: bidirectional, allosteric signaling machines," Cell, vol. 110, no. 6, pp. 673-687, 2002.

[2] J. L. Guan, J. E. Trevithick, and R. O. Hynes, "Fibronectin/ integrin interaction induces tyrosine phosphorylation of a 120kDa protein," Cell regulation, vol. 2, no. 11, pp. 951-964, 1991.

[3] M. D. Schaller, C. A. Borgman, B. S. Cobb, R. R. Vines, A. B. Reynolds, and J. Thomas Parsons, "pp125FAK, a structurally distinctive protein-tyrosine kinase associated with focal adhesions," Proceedings of the National Academy of Sciences of the United States of America, vol. 89, no. 11, pp. 5192-5196, 1992.

[4] S. K. Hanks, M. B. Calalb, M. C. Harper, and S. K. Patel, "Focal adhesion protein-tyrosine kinase phosphorylated in response to cell attachment to fibronectin," Proceedings of the National Academy of Sciences of the United States of America, vol. 89, no. 18, pp. 8487-8491, 1992.

[5] J. Zhao and J.-L. Guan, "Signal transduction by focal adhesion kinase in cancer," Cancer and Metastasis Reviews, vol. 28, no. 1-2, pp. 35-49, 2009.

[6] L. A. Cooper, T. L. Shen, and J. L. Guan, "Regulation of focal adhesion kinase by its amino-terminal domain through an autoinhibitory interaction," Molecular and Cellular Biology, vol. 23, no. 22, pp. 8030-8041, 2003.

[7] J. M. Dunty, V. Gabarra-Niecko, M. L. King, D. F. J. Ceccarelli, M. J. Eck, and M. D. Schaller, "FERM domain interaction promotes FAK signaling," Molecular and Cellular Biology, vol. 24, no. 12, pp. 5353-5368, 2004. 
[8] D. Lietha, X. Cai, D. F. J. Ceccarelli, Y. Li, M. D. Schaller, and M. J. Eck, "Structural basis for the autoinhibition of focal adhesion kinase," Cell, vol. 129, no. 6, pp. 1177-1187, 2007.

[9] D. C. Han and J.-L. Guan, "Association of focal adhesion kinase with Grb7 and its role in cell migration," The Journal of Biological Chemistry, vol. 274, no. 34, pp. 24425-24430, 1999.

[10] D. C. Han, T.-L. Shen, and J.-L. Guan, "Role of Grb7 targeting to focal contacts and its phosphorylation by focal adhesion kinase in regulation of cell migration," The Journal of Biological Chemistry, vol. 275, no. 37, pp. 28911-28917, 2000.

[11] H. R. Reiske, S.-C. Kao, L. A. Cary, J.-L. Guan, J.-F. Lai, and H.-C. Chen, "Requirement of phosphatidylinositol 3-kinase in focal adhesion kinase-promoted cell migration," The Journal of Biological Chemistry, vol. 274, no. 18, pp. 12361-12366, 1999.

[12] M. D. Schaller, J. D. Hildebrand, J. D. Shannon, J. W. Fox, R. R. Vines, and J. T. Parsons, "Autophosphorylation of the focal adhesion kinase, pp125FAK, directs SH2-dependent binding of pp60src," Molecular and Cellular Biology, vol. 14, no. 3, pp. 16801688, 1994.

[13] M. B. Calalb, T. R. Polte, and S. K. Hanks, “Tyrosine phosphorylation of focal adhesion kinase at sites in the catalytic domain regulates kinase activity: a role for Src family kinases," Molecular and Cellular Biology, vol. 15, no. 2, pp. 954-963, 1995.

[14] D. D. Schlaepfer and T. Hunter, "Evidence for in vivo phosphorylation of the Grb2 SH2-domain binding site on focal adhesion kinase by Src-family protein-tyrosine kinases," Molecular and Cellular Biology, vol. 16, no. 10, pp. 5623-5633, 1996.

[15] D. D. Schlaepfer, S. K. Hanks, T. Hunter, and P. Van der Geer, "Integrin-mediated signal transduction linked to Ras pathway by GRB2 binding to focal adhesion kinase," Nature, vol. 372, no. 6508, pp. 786-791, 1994.

[16] T.-L. Shen and J.-L. Guan, "Differential regulation of cell migration and cell cycle progression by FAK complexes with Src, PI3K, Grb7 and Grb2 in focal contacts," FEBS Letters, vol. 499, no. 1-2, pp. 176-181, 2001.

[17] G. W. McLean, N. O. Carragher, E. Avizienyte, J. Evans, V. G. Brunton, and M. C. Frame, "The role of focal-adhesion kinase in cancer-a new therapeutic opportunity," Nature Reviews Cancer, vol. 5, no. 7, pp. 505-515, 2005.

[18] A. Cretu and P. C. Brooks, "Impact of the non-cellular tumor microenvironment on metastasis: potential therapeutic and imaging opportunities," Journal of Cellular Physiology, vol. 213, no. 2, pp. 391-402, 2007.

[19] T. L. Whiteside, "The tumor microenvironment and its role in promoting tumor growth," Oncogene, vol. 27, no. 45, pp. 59045912, 2008.

[20] H. Ungefroren, S. Sebens, D. Seidl, H. Lehnert, and R. Hass, "Interaction of tumor cells with the microenvironment," Cell Communication and Signaling, vol. 9, article 18, 2011.

[21] Y.-N. Kim, K. H. Koo, J. Y. Sung, U.-J. Yun, and H. Kim, "Anoikis resistance: an essential prerequisite for tumor metastasis," International Journal of Cell Biology, vol. 2012, Article ID 306879, 11 pages, 2012.

[22] P. J. Reddig and R. L. Juliano, "Clinging to life: cell to matrix adhesion and cell survival," Cancer and Metastasis Reviews, vol. 24, no. 3, pp. 425-439, 2005.

[23] V. Bouchard, M.-J. Demers, S. Thibodeau et al., "Fak/Src signaling in human intestinal epithelial cell survival and anoikis: differentiation state-specific uncoupling with the PI3-K/Akt-1 and MEK/Erk pathways," Journal of Cellular Physiology, vol. 212, no. 3, pp. 717-728, 2007.
[24] J. C. Horowitz, D. S. Rogers, V. Sharma et al., "Combinatorial activation of FAK and AKT by transforming growth factor$\beta 1$ confers an anoikis-resistant phenotype to myofibroblasts," Cellular Signalling, vol. 19, no. 4, pp. 761-771, 2007.

[25] Y. Zhang, H. Lu, P. Dazin, and Y. Kapila, "Squamous cell carcinoma cell aggregates escape suspension-induced, p53mediated anoikis: fibronectin and integrin $\alpha \mathrm{v}$ mediate survival signals through focal adhesion kinase," The Journal of Biological Chemistry, vol. 279, no. 46, pp. 48342-48349, 2004.

[26] P. Kamarajan and Y. L. Kapila, "An altered fibronectin matrix induces anoikis of human squamous cell carcinoma cells by suppressing integrin alpha v levels and phosphorylation of FAK and ERK," Apoptosis, vol. 12, no. 12, pp. 2221-2231, 2007.

[27] M. S. Duxbury, H. Ito, M. J. Zinner, S. W. Ashley, and E. E. Whang, "Focal adhesion kinase gene silencing promotes anoikis and suppresses metastasis of human pancreatic adenocarcinoma cells," Surgery, vol. 135, no. 5, pp. 555-562, 2004.

[28] Y. Sonoda, Y. Matsumoto, M. Funakoshi, D. Yamamoto, S. K. Hanks, and T. Kasahara, "Anti-apoptotic role of focal adhesion kinase (FAK): induction of inhibitor-of-apoptosis proteins and apoptosis suppression by the overexpression of FAK in a human leukemic cell line, HL-60," Journal of Biological Chemistry, vol. 275, no. 21, pp. 16309-16315, 2000.

[29] D. Huang, M. Khoe, M. Befekadu et al., "Focal adhesion kinase mediates cell survival via NF- $\kappa$ B and ERK signaling pathways," The American Journal of Physiology-Cell Physiology, vol. 292, no. 4, pp. C1339-C1352, 2007.

[30] E. Kurenova, L.-H. Xu, X. Yang et al., "Focal adhesion kinase suppresses apoptosis by binding to the death domain of receptor-interacting protein," Molecular and Cellular Biology, vol. 24, no. 10, pp. 4361-4371, 2004.

[31] K. B. Dunn, M. Heffler, and V. M. Golubovskaya, "Evolving therapies and FAK inhibitors for the treatment of cancer," AntiCancer Agents in Medicinal Chemistry, vol. 10, no. 10, pp. 722734, 2010.

[32] J.-H. Zhao, H. Reiske, and J.-L. Guan, "Regulation of the cell cycle by focal adhesion kinase," The Journal of Cell Biology, vol. 143, no. 7, pp. 1997-2008, 1998.

[33] J. Zhao, R. Pestell, and J.-L. Guan, “Transcriptional activation of cyclin D1 promoter by FAK contributes to cell cycle progression," Molecular Biology of the Cell, vol. 12, no. 12, pp. 4066-4077, 2001.

[34] Q. Ding, J. R. Grammer, M. A. Nelson, J.-L. Guan, J. E. Stewart Jr., and C. L. Gladson, "p27Kip1 and cyclin D1 are necessary for focal adhesion kinase regulation of cell cycle progression in glioblastoma cells propagated in vitro and in vivo in the scid mouse brain," The Journal of Biological Chemistry, vol. 280, no. 8, pp. 6802-6815, 2005.

[35] J. T. Zilfou and S. W. Lowe, "Tumor suppressive functions of p53," Cold Spring Harbor perspectives in biology, vol. 1, no. 5, 2009.

[36] V. M. Golubovskaya, R. Finch, and W. G. Cance, "Direct interaction of the N-terminal domain of focal adhesion kinase with the N-terminal transactivation domain of p53," The Journal of Biological Chemistry, vol. 280, no. 26, pp. 25008-25021, 2005.

[37] S.-T. Lim, X. L. Chen, Y. Lim et al., "Nuclear FAK promotes cell proliferation and survival through FERM-enhanced p53 degradation," Molecular Cell, vol. 29, no. 1, pp. 9-22, 2008.

[38] M. H. A. M. van Miltenburg, M. J. van Nimwegen, I. Tijdens et al., "Mammary gland-specific ablation of focal adhesion kinase reduces the incidence of p53-mediated mammary tumour 
formation," British Journal of Cancer, vol. 110, no. 11, pp. 27472755, 2014.

[39] M. Vicente-Manzanares, D. J. Webb, and A. R. Horwitz, "Cell migration at alance," Journal of Cell Science, vol. 118, no. 21, pp. 4917-4919, 2005.

[40] Q. Shi and D. Boettiger, "A novel mode for integrin-mediated signaling: tethering is required for phosphorylation of FAK Y397," Molecular Biology of the Cell, vol. 14, no. 10, pp. 43064315, 2003.

[41] L. A. Cary, D. C. Han, T. R. Polte, S. K. Hanks, and J.-L. Guan, "Identification of p130(Cas) as a mediator of focal adhesion kinase-promoted cell migration," The Journal of Cell Biology, vol. 140, no. 1, pp. 211-221, 1998.

[42] D. J. Webb, K. Donais, L. A. Whitmore et al., "FAK-Src signalling through paxillin, ERK and MLCK regulates adhesion disassembly," Nature Cell Biology, vol. 6, no. 2, pp. 154-161, 2004.

[43] C. Huang, Z. Rajfur, C. Borchers, M. D. Schaller, and K. Jacobson, "JNK phosphorylates paxillin and regulates cell migration," Nature, vol. 424, no. 6945, pp. 219-223, 2003.

[44] P.-Y. Chu, L.-Y. Huang, C.-H. Hsu et al., "Tyrosine phosphorylation of growth factor receptor-bound protein-7 by focal adhesion kinase in the regulation of cell migration, proliferation, and tumorigenesis," The Journal of Biological Chemistry, vol. 284, no. 30, pp. 20215-20226, 2009.

[45] T. L. Shen, D. C. Han, and J. L. Guan, "Association of Grb7 with phosphoinositides and its role in the regulation of cell migration., The Journal of Biological Chemistry, vol. 277, no. 32, pp. 29069-29077, 2002.

[46] N. O. Carragher, M. A. Westhoff, V. J. Fincham, M. D. Schaller, and M. C. Frame, "A novel role for FAK as a protease-targeting adaptor protein: regulation by 422 ERK and Src," Current Biology, vol. 13, no. 16, pp. 1442-1450, 2003.

[47] S. J. Franco, M. A. Rodgers, B. J. Perrin et al., "Calpain-mediated proteolysis of talin regulates adhesion dynamics," Nature Cell Biology, vol. 6, no. 10, pp. 977-983, 2004.

[48] K. T. Chan, D. A. Bennin, and A. Huttenlocher, "Regulation of adhesion dynamics by calpain-mediated proteolysis of focal adhesion kinase (FAK)," The Journal of Biological Chemistry, vol. 285, no. 15, pp. 11418-11426, 2010.

[49] M. Yilmaz and G. Christofori, "EMT, the cytoskeleton, and cancer cell invasion," Cancer and Metastasis Reviews, vol. 28, no. 1-2, pp. 15-33, 2009.

[50] S. Krugmann, I. Jordens, K. Gevaert, M. Driessens, J. Vandekerckhove, and A. Hall, "Cdc42 induces filopodia by promoting the formation of an IRSp53:Mena complex," Current Biology, vol. 11, no. 21, pp. 1645-1655, 2001.

[51] A. J. Ridley, "Rho GTPases and actin dynamics in membrane protrusions and vesicle trafficking," Trends in Cell Biology, vol. 16, no. 10, pp. 522-529, 2006.

[52] J. D. Hildebrand, J. M. Taylor, and J. T. Parsons, "An SH3 domain-containing GTPase-activating protein for Rho and Cdc42 associates with focal adhesion kinase," Molecular and Cellular Biology, vol. 16, no. 6, pp. 3169-3178, 1996.

[53] X. Wu, S. Suetsugu, L. A. Cooper, T. Takenawa, and J.-L. Guan, "Focal adhesion kinase regulation of N-WASP subcellular localization and function," The Journal of Biological Chemistry, vol. 279, no. 10, pp. 9565-9576, 2004.

[54] P. S. Steeg, "Tumor metastasis: Mechanistic insights and clinical challenges," Nature Medicine, vol. 12, no. 8, pp. 895-904, 2006.

[55] Y. Lim, I. Han, J. Jeon, H. Park, Y.-Y. Bahk, and E.-S. Oh, "Phosphorylation of focal adhesion kinase at tyrosine 861 is crucial for ras transformation of fibroblasts," The Journal of Biological Chemistry, vol. 279, no. 28, pp. 29060-29065, 2004.

[56] S. Lamouille, J. Xu, and R. Derynck, "Molecular mechanisms of epithelial-mesenchymal transition," Nature Reviews Molecular Cell Biology, vol. 15, no. 3, pp. 178-196, 2014.

[57] E. Avizienyte and M. C. Frame, "Src and FAK signalling controls adhesion fate and the epithelial-to- mesenchymal transition," Current Opinion in Cell Biology, vol. 17, no. 5, pp. 542-547, 2005.

[58] F. J. Sulzmaier, C. Jean, and D. D. Schlaepfer, "FAK in cancer: mechanistic findings and clinical applications," Nature Reviews Cancer, vol. 14, no. 9, pp. 598-610, 2014.

[59] A. Serrels, M. Canel, V. G. Brunton, and M. C. Frame, "Src/FAKmediated regulation of E-cadherin as a mechanism for controlling collective cell movement: insights from in vivo imaging," Cell Adhesion \& Migration, vol. 5, no. 4, pp. 360-365, 2011.

[60] C. Cicchini, I. Laudadio, F. Citarella et al., "TGF $\beta$-induced EMT requires focal adhesion kinase (FAK) signaling," Experimental Cell Research, vol. 314, no. 1, pp. 143-152, 2008.

[61] L. J. Kornberg, "Focal adhesion kinase and its potential involvement in tumor invasion and metastasis," Head \& Neck, vol. 20, no. 8, pp. 745-752, 1998.

[62] R.-K. Li, W.-Y. Zhao, F. Fang et al., "Lysyl oxidase-like 4 (LOXL4) promotes proliferation and metastasis of gastric cancer via FAK/Src pathway," Journal of Cancer Research and Clinical Oncology, vol. 141, no. 2, pp. 269-281, 2015.

[63] D. A. Hsia, S. K. Mitra, C. R. Hauck et al., "Differential regulation of cell motility and invasion by FAK," The Journal of Cell Biology, vol. 160, no. 5, pp. 753-767, 2003.

[64] S. K. Mitra, S.-T. Lim, A. Chi, and D. D. Schlaepfer, "Intrinsic focal adhesion kinase activity controls orthotopic breast carcinoma metastasis via the regulation of urokinase plasminogen activator expression in a syngeneic tumor model," Oncogene, vol. 25, no. 32, pp. 4429-4440, 2006.

[65] X. Kong, G. Li, Y. Yuan et al., "MicroRNA-7 inhibits epithelialto-mesenchymal transition and metastasis of breast cancer cells via targeting FAK expression," PLoS ONE, vol. 7, no. 8, Article ID e41523, 2012.

[66] H. Jiang, L. Liu, J. Ye, H. Liu, S. Xing, and Y. Wu, "Focal adhesion kinase serves as a marker of cervical lymph node metastasis and is a potential therapeutic target in tongue cancer," Journal of Cancer Research and Clinical Oncology, vol. 136, no. 9, pp. 12951302, 2010.

[67] L.-H. Xu, X. Yang, R. J. Craven, and W. G. Cance, "The COOHterminal domain of the focal adhesion kinase induces loss of adhesion and cell death in human tumor cells," Cell Growth and Differentiation, vol. 9, no. 12, pp. 999-1005, 1998.

[68] K. Tsutsumi, T. Kasaoka, H. M. Park, H. Nishiyama, M. Nakajima, and T. Honda, "Tumor growth inhibition by synthetic and expressed siRNA targeting focal adhesion kinase," International Journal of Oncology, vol. 33, no. 1, pp. 215-244, 2008.

[69] A. Richardson and J. T. Parsons, "A mechanism for regulation of the adhesion-associated proteintyrosine kinase pp125FAK," Nature, vol. 380, no. 6574, pp. 538-540, 1996.

[70] M. J. van Nimwegen, S. Verkoeijen, L. van Buren, D. Burg, and B. van de Water, "Requirement for focal adhesion kinase in the early phase of mammary adenocarcinoma lung metastasis formation," Cancer Research, vol. 65, no. 11, pp. 4698-4706, 2005.

[71] C. R. Hauck, D. A. Hsia, X. S. Puente, D. A. Cheresh, and D. D. Schlaepfer, "FRNK blocks v-Src-stimulated invasion and experimental metastases without effects on cell motility or growth," The EMBO Journal, vol. 21, no. 23, pp. 6289-6302, 2002. 
[72] C. Li, X. Zhang, L. Cheng et al., "RNA interference targeting human FAK and EGFR suppresses human non-small-cell lung cancer xenograft growth in nude mice," Cancer Gene Therapy, vol. 20, no. 2, pp. 101-108, 2013.

[73] R. Bjerkvig, B. B. Tysnes, K. S. Aboody, J. Najbauer, and A. J. A. Terzis, "The origin of the cancer stem cell: current controversies and new insights," Nature Reviews Cancer, vol. 5, no. 11, pp. 899904, 2005.

[74] M. Dean, T. Fojo, and S. Bates, "Tumour stem cells and drug resistance," Nature Reviews Cancer, vol. 5, no. 4, pp. 275-284, 2005.

[75] M. Luo, H. Fan, T. Nagy et al., "Mammary epithelial-specific ablation of the focal adhesion kinase suppresses mammary tumorigenesis by affecting mammary cancer stem/progenitor cells," Cancer Research, vol. 69, no. 2, pp. 466-474, 2009.

[76] H. Fan and J.-L. Guan, "Compensatory function of Pyk2 protein in the promotion of focal adhesion kinase (FAK)null mammary cancer stem cell tumorigenicity and metastatic activity," Journal of Biological Chemistry, vol. 286, no. 21, pp. 18573-18582, 2011.

[77] M. Schober and E. Fuchs, "Tumor-initiating stem cells of squamous cell carcinomas and their control by TGF-beta and integrin/focal adhesion kinase (FAK) signaling," Proceedings of the National Academy of Sciences of the United States of America, vol. 108, no. 26, pp. 10544-10549, 2011.

[78] M. Luo, X. Zhao, S. Chen, S. Liu, M. S. Wicha, and J.-L. Guan, "Distinct FAK activities determine progenitor and mammary stem cell characteristics," Cancer Research, vol. 73, no. 17, pp. 5591-5602, 2013.

[79] H. Fan, X. Zhao, S. Sun, M. Luo, and J.-L. Guan, "Function of focal adhesion kinase scaffolding to mediate endophilin A2 phosphorylation promotes epithelial-mesenchymal transition and mammary cancer stem cell activities in vivo," The Journal of Biological Chemistry, vol. 288, no. 5, pp. 3322-3333, 2013.

[80] F. R. Balkwill, M. Capasso, and T. Hagemann, "The tumor microenvironment at a glance," Journal of Cell Science, vol. 125, no. 23, pp. 5591-5596, 2012.

[81] D. S. Harburger and D. A. Calderwood, "Integrin signalling at a glance," Journal of Cell Science, vol. 122, no. 2, pp. 159-163, 2009.

[82] D. T. Butcher, T. Alliston, and V. M. Weaver, "A tense situation: forcing tumour progression," Nature Reviews Cancer, vol. 9, no. 2, pp. 108-122, 2009.

[83] S. L. Payne, B. Fogelgren, A. R. Hess et al., "Lysyl oxidase regulates breast cancer cell migration and adhesion through a hydrogen peroxide-mediated mechanism," Cancer Research, vol. 65, no. 24, pp. 11429-11436, 2005.

[84] R. Laczko, K. M. Szauter, M. K. Jansen et al., "Active lysyl oxidase (LOX) correlates with focal adhesion kinase (FAK)/paxillin activation and migration in invasive astrocytes," Neuropathology and Applied Neurobiology, vol. 33, no. 6, pp. 631-643, 2007.

[85] A.-M. Baker, D. Bird, G. Lang, T. R. Cox, and J. T. Erler, "Lysyl oxidase enzymatic function increases stiffness to drive colorectal cancer progression through FAK," Oncogene, vol. 32, no. 14, pp. 1863-1868, 2013.

[86] K. R. Levental, H. Yu, L. Kass et al., "Matrix crosslinking forces tumor progression by enhancing integrin signaling," Cell, vol. 139, no. 5, pp. 891-906, 2009.

[87] J. K. Mouw, Y. Yui, L. Damiano et al., “Tissue mechanics modulate microRNA-dependent PTEN expression to regulate malignant progression," Nature Medicine, vol. 20, no. 4, pp. 360-367, 2014.
[88] Y. H. Bae, K. L. Mui, B. Y. Hsu et al., "A FAK-Cas-Rac-lamellipodin signaling module transduces extracellular matrix stiffness into mechanosensitive cell cycling," Science Signaling, vol. 7, no. 330, p. ra57, 2014.

[89] B. Tavora, S. Batista, L. E. Reynolds et al., "Endothelial FAK is required for tumour angiogenesis," EMBO Molecular Medicine, vol. 2, no. 12, pp. 516-528, 2010.

[90] T.-L. Shen, A. Y.-J. Park, A. Alcaraz et al., “Conditional knockout of focal adhesion kinase in endothelial cells reveals its role in angiogenesis and vascular development in late embryogenesis," Journal of Cell Biology, vol. 169, no. 6, pp. 941-952, 2005.

[91] R. Braren, H. Hu, Y. H. Kim, H. E. Beggs, L. F. Reichardt, and R. Wang, "Endothelial FAK is essential for vascular network stability, cell survival, and lamellipodial formation," The Journal of Cell Biology, vol. 172, no. 1, pp. 151-162, 2006.

[92] T. R. Polte, A. J. Naftilan, and S. K. Hanks, "Focal adhesion kinase is abundant in developing blood vessels and elevation of its phosphotyrosine content in vascular smooth muscle cells is a rapid response to angiotensin II," Journal of Cellular Biochemistry, vol. 55, no. 1, pp. 106-119, 1994.

[93] H. Haskell, M. Natarajan, T. P. Hecker et al., "Focal adhesion kinase is expressed in the angiogenic blood vessels of malignant astrocytic tumors in vivo and promotes capillary tube formation of brain microvascular endothelial cells," Clinical Cancer Research, vol. 9, no. 6, pp. 2157-2165, 2003.

[94] L. H. Romer, N. McLean, C. E. Turner, and K. Burridge, "Tyrosine kinase activity, cytoskeletal organization, and motility in human vascular endothelial cells," Molecular Biology of the Cell, vol. 5, no. 3, pp. 349-361, 1994.

[95] J. H. Qi and L. Claesson-Welsh, "VEGF-induced activation of phosphoinositide 3-kinase is dependent on focal adhesion kinase," Experimental Cell Research, vol. 263, no. 1, pp. 173-182, 2001.

[96] I. Kim, H. G. Kim, S.-O. Moon et al., "Angiopoietin-1 induces endothelial cell sprouting through the activation of focal adhesion kinase and plasmin secretion," Circulation Research, vol. 86, no. 9, pp. 952-959, 2000.

[97] C. Jean, X. L. Chen, J.-O. Nam et al., "Inhibition of endothelial FAK activity prevents tumor metastasis by enhancing barrier function," The Journal of Cell Biology, vol. 204, no. 2, pp. 247263, 2014.

[98] R. Noy and J. W. Pollard, "Tumor-associated macrophages: from mechanisms to therapy," Immunity, vol. 41, no. 1, pp. 49-61, 2014.

[99] M. Y. Abshire, K. S. Thomas, K. A. Owen, and A. H. Bouton, "Macrophage motility requires distinct alpha5betal/FAK and alpha4betal/paxillin signaling events," Journal of Leukocyte Biology, vol. 89, no. 2, pp. 251-257, 2011.

[100] J. B. Stokes, S. J. Adair, J. K. Slack-Davis et al., "Inhibition of focal adhesion kinase by PF-562,271 inhibits the growth and metastasis of pancreatic cancer concomitant with altering the tumor microenvironment," Molecular Cancer Therapeutics, vol. 10, no. 11, pp. 2135-2145, 2011.

[101] B. Thapa, B.-H. Koo, Y.-H. Kim, H.-J. Kwon, and D.-S. Kim, "Plasminogen activator inhibitor-1 regulates infiltration of macrophages into melanoma via phosphorylation of FAK-Tyr ${ }^{25}$," Biochemical and Biophysical Research Communications, vol. 450, no. 4, pp. 1696-1701, 2014.

[102] P. C. Chen, H. C. Cheng, J. Wang et al., "Prostate cancer-derived CCN3 induces M2 macrophage infiltration and contributes to angiogenesis in prostate cancer microenvironment," Oncotarget, vol. 5, no. 6, pp. 1595-1608, 2014. 
[103] R. Chen, Z. Zhang, Z. Xue et al., "Focal adhesion kinase (FAK) siRNA inhibits human hypertrophic scar by suppressing integrin $\alpha$, TGF- $\beta$ and $\alpha$-SMA," Cell Biology International, vol. 38, no. 7, pp. 803-808, 2014.

[104] T. Chanmee, P. Ontong, K. Konno, and N. Itano, “Tumorassociated macrophages as major players in the tumor microenvironment," Cancers, vol. 6, no. 3, pp. 1670-1690, 2014.

[105] B. Rothhut, C. Ghoneim, F. Antonicelli, and M. Soula-Rothhut, "Epidermal growth factor stimulates matrix metalloproteinase9 expression and invasion in human follicular thyroid carcinoma cells through Focal adhesion kinase," Biochimie, vol. 89, no. 5, pp. 613-624, 2007.

[106] Q. Wang, Y. Wang, D. Fritz, D. Rajshankar, G. P. Downey, and C. A. McCulloch, "Interactions of the protein-tyrosine phosphatase-alpha with the focal adhesion targeting domain of focal adhesion kinase are involved in interleukin-1 signaling in fibroblasts," The Journal of Biological Chemistry, vol. 289, no. 26, pp. 18427-18441, 2014.

[107] S. Ramanathan and N. Jagannathan, "Tumor associated macrophage: a review on the phenotypes, traits and functions," Iranian Journal of Cancer Prevention, vol. 7, no. 1, pp. 1-8, 2014.

[108] J. Zhu, Y.-S. Wang, J. Zhang et al., "Focal adhesion kinase signaling pathway participates in the formation of choroidal neovascularization and regulates the proliferation and migration of choroidal microvascular endothelial cells by acting through HIF-1 and VEGF expression in RPE cells," Experimental Eye Research, vol. 88, no. 5, pp. 910-918, 2009.

[109] E. A. Sheta, M. A. Harding, M. R. Conaway, and D. Theodorescu, "Focal adhesion kinase, Rap1, and transcriptional induction of vascular endothelial growth factor," Journal of the National Cancer Institute, vol. 92, no. 13, pp. 1065-1073, 2000.

[110] L. Neff, M. Zeisel, V. Druet et al., "ERK 1/2- and JNKs-dependent synthesis of interleukins 6 and 8 by fibroblast-like synoviocytes stimulated with protein I/II, a modulin from oral streptococci, requires focal adhesion kinase," Journal of Biological Chemistry, vol. 278, no. 30, pp. 27721-27728, 2003.

[111] J. Eitel, T. Heise, U. Thiesen, and P. Dersch, "Cell invasion and IL-8 production pathways initiated by YadA of Yersinia pseudotuberculosis require common signalling molecules (FAK, c-Src, Ras) and distinct cell factors," Cellular Microbiology, vol. 7, no. 1, pp. 63-77, 2005.

[112] M. R. Shurin, "Dual role of immunomodulation by anticancer chemotherapy," Nature Medicine, vol. 19, no. 1, pp. 20-22, 2013.

[113] M. M. Mueller and N. E. Fusenig, "Friends or foes-bipolar effects of the tumour stroma in cancer," Nature Reviews Cancer, vol. 4, no. 11, pp. 839-849, 2004.

[114] R. Kalluri and M. Zeisberg, "Fibroblasts in cancer," Nature Reviews Cancer, vol. 6, no. 5, pp. 392-401, 2006.

[115] H. E. Barker, D. Bird, G. Lang, and J. T. Erler, "Tumor-secreted LOXL2 activates fibroblasts through fak signaling," Molecular Cancer Research, vol. 11, no. 11, pp. 1425-1436, 2013.

[116] N. K. Zouq, J. A. Keeble, J. Lindsay et al., "FAK engages multiple pathways to maintain survival of fibroblasts and epitheliadifferential roles for paxillin and p130Cas," Journal of Cell Science, vol. 122, no. 3, pp. 357-367, 2009.

[117] G. W. McLean, N. H. Komiyama, B. Serrels et al., "Specific deletion of focal adhesion kinase suppresses tumor formation and blocks malignant progression," Genes \& Development, vol. 18, no. 24, pp. 2998-3003, 2004.

[118] R. Navab, D. Strumpf, B. Bandarchi et al., "Prognostic geneexpression signature of carcinoma-associated fibroblasts in non-small cell lung cancer," Proceedings of the National Academy of Sciences of the United States of America, vol. 108, no. 17, pp. 7160-7165, 2011.

[119] T. M. Weiner, E. T. Liu, R. J. Craven, and W. G. Cance, "Expression of focal adhesion kinase gene and invasive cancer," The Lancet, vol. 342, no. 8878, pp. 1024-1025, 1993.

[120] L. Tremblay, W. Hauck, A. G. Aprikian, L. R. Begin, A. Chapdelaine, and S. Chevalier, "Focal adhesion kinase $\left(\mathrm{pp} 125^{F A K}\right)$ expression, activation and association with paxillin and $\mathrm{p} 50^{\text {CSK }}$ in human metastatic prostate carcinoma," International Journal of Cancer, vol. 68, no. 2, pp. 164-171, 1996.

[121] P. L. Judson, X. He, W. G. Cance, and L. Van Le, “Overexpression of focal adhesion kinase, a protein tyrosine kinase, in ovarian carcinoma," Cancer, vol. 86, no. 8, pp. 1551-1556, 1999.

[122] A. L. Lark, C. A. Livasy, B. Calvo et al., "Overexpression of focal adhesion kinase in primary colorectal carcinomas and colorectal liver metastases: immunohistochemistry and realtime PCR analyses," Clinical Cancer Research, vol. 9, no. 1 I, pp. 215-222, 2003.

[123] L. V. Owens, L. Xu, R. J. Craven et al., "Overexpression of the focal adhesion kinase (p125FAK) in invasive human tumors," Cancer Research, vol. 55, no. 13, pp. 2752-2755, 1995.

[124] M. Agochiya, V. G. Brunton, D. W. Owens et al., "Increased dosage and amplification of the focal adhesion kinase gene in human cancer cells," Oncogene, vol. 18, no. 41, pp. 5646-5653, 1999.

[125] M. Canel, P. Secades, J. P. Rodrigo et al., “Overexpression of focal adhesion kinase in head and neck squamous cell carcinoma is independent of fak gene copy number," Clinical Cancer Research, vol. 12, no. 11 I, pp. 3272-3279, 2006.

[126] V. Golubovskaya, A. Kaur, and W. Cance, "Cloning and characterization of the promoter region of human focal adhesion kinase gene: nuclear factor kappa B and p53 binding sites," Biochimica et Biophysica Acta: Gene Structure and Expression, vol. 1678, no. 2-3, pp. 111-125, 2004.

[127] V. M. Golubovskaya, R. Finch, F. Kweh et al., "p53 regulates FAK expression in human tumor cells," Molecular Carcinogenesis, vol. 47, no. 5, pp. 373-382, 2008.

[128] V. M. Golubovskaya, K. Conway-Dorsey, S. N. Edmiston et al., "FAK overexpression and p53 mutations are highly correlated in human breast cancer," International Journal of Cancer, vol. 125, no. 7, pp. 1735-1738, 2009.

[129] J. Ding, S. Huang, S. Wu et al., "Gain of miR-151 on chromosome 8 q24.3 facilitates tumour cell migration and spreading through downregulating RhoGDIA," Nature Cell Biology, vol. 12, no. 4, pp. 390-399, 2010.

[130] N. M. Han, R. Y. Declan Fleming, S. A. Curley, and G. E. Gallick, "Overexpression of focal adhesion kinase (p125FAK) in human colorectal carcinoma liver metastases: independence from c-src or c-yes activation," Annals of Surgical Oncology, vol. 4, no. 3, pp. 264-268, 1997.

[131] M. Abdel-Ghany, H.-C. Cheng, R. C. Elble, and B. U. Pauli, "Focal adhesion kinase activated by beta(4) integrin ligation to mCLCA1 mediates early metastatic growth," The Journal of Biological Chemistry, vol. 277, no. 37, pp. 34391-34400, 2002.

[132] I. Eke, Y. Deuse, S. Hehlgans et al., “ $\beta_{1}$ integrin/FAK/cortactin signaling is essential for human head and neck cancer resistance to radiotherapy," The Journal of Clinical Investigation, vol. 122, no. 4, pp. 1529-1540, 2012.

[133] T. Shibue and R. A. Weinberg, "Integrin $\beta 1$-focal adhesion kinase signaling directs the proliferation of metastatic cancer 
cells disseminated in the lungs," Proceedings of the National Academy of Sciences of the United States of America, vol. 106, no. 25, pp. 10290-10295, 2009.

[134] L. V. Owens, L. Xu, G. A. Dent et al., "Focal adhesion kinase as a marker of invasive potential in differentiated human thyroid cancer," Annals of Surgical Oncology, vol. 3, no. 1, pp. 100-105, 1996.

[135] C. Recher, L. Ysebaert, O. Beyne-Rauzy et al., "Expression of focal adhesion kinase in acute myeloid leukemia is associated with enhanced blast migration, increased cellularity, and poor prognosis," Cancer Research, vol. 64, no. 9, pp. 3191-3197, 2004.

[136] A. Albasri, W. Fadhil, J. H. Scholefield, L. G. Durrant, and M. Ilyas, "Nuclear expression of phosphorylated focal adhesion kinase is associated with poor prognosis in human colorectal cancer," Anticancer Research, vol. 34, no. 8, pp. 3969-3974, 2014.

[137] J. K. Slack-Davis, K. H. Martin, R. W. Tilghman et al., "Cellular characterization of a novel focal adhesion kinase inhibitor," The Journal of Biological Chemistry, vol. 282, no. 20, pp. 1484514852, 2007.

[138] Q. Shi, A. B. Hjelmeland, S. T. Keir et al., "A novel low-molecular weight inhibitor of focal adhesion kinase, TAE226, inhibits glioma growth," Molecular Carcinogenesis, vol. 46, no. 6, pp. 488-496, 2007.

[139] V. M. Golubovskaya, C. Virnig, and W. G. Cance, "TAE226induced apoptosis in breast cancer cells with overexpressed Src or EGFR," Molecular Carcinogenesis, vol. 47, no. 3, pp. 222-234, 2008.

[140] N. Kurio, T. Shimo, T. Fukazawa et al., "Anti-tumor effect in human breast cancer by TAE226, a dual inhibitor for FAK and IGF-IR in vitro and in vivo," Experimental Cell Research, vol. 317, no. 8, pp. 1134-1146, 2011.

[141] N. Kurio, T. Shimo, T. Fukazawa et al., "Anti-tumor effect of a novel FAK inhibitor TAE226 against human oral squamous cell carcinoma," Oral Oncology, vol. 48, no. 11, pp. 1159-1170, 2012.

[142] I. Tanjoni, C. Walsh, S. Uryu et al., "PND-1186 FAK inhibitor selectively promotes tumor cell apoptosis in three-dimensional environments," Cancer Biology and Therapy, vol. 9, no. 10, pp. 764-777, 2010.

[143] C. Walsh, I. Tanjoni, S. Uryu et al., "Oral delivery of PND-1186 FAK inhibitor decreases tumor growth and spontaneous breast to lung metastasis in pre-clinical models," Cancer Biology \& Therapy, vol. 9, no. 10, pp. 778-790, 2010.

[144] W. G. Roberts, E. Ung, P. Whalen et al., "Antitumor activity and pharmacology of a selective focal adhesion kinase inhibitor, PF562,271," Cancer Research, vol. 68, no. 6, pp. 1935-1944, 2008.

[145] J. R. Infante, D. R. Camidge, L. R. Mileshkin et al., "Safety, pharmacokinetic, and pharmacodynamic phase I dose-escalation trial of PF-00562271, an inhibitor of focal adhesion kinase, in advanced solid tumors," Journal of Clinical Oncology, vol. 30, no. 13, pp. 1527-1533, 2012.

[146] E. V. Kurenova, D. L. Hunt, D. He, A. T. Magis, D. A. Ostrov, and W. G. Cance, "Small molecule chloropyramine hydrochloride (C4) targets the binding site of focal adhesion kinase and vascular endothelial growth factor receptor 3 and suppresses breast cancer growth in vivo," Journal of Medicinal Chemistry, vol. 52, no. 15, pp. 4716-4724, 2009.

[147] D. A. Ucar, E. Kurenova, T. J. Garrett et al., "Disruption of the protein interaction between FAK and IGF-1R inhibits melanoma tumor growth," Cell Cycle, vol. 11, no. 17, pp. 3250-3259, 2012.

[148] V. M. Golubovskaya, N. L. Palma, M. Zheng et al., "A small-molecule inhibitor, $5^{\prime}$-o-tritylthymidine, targets FAK and
Mdm-2 interaction, and blocks breast and colon tumorigenesis in vivo," Anti-Cancer Agents in Medicinal Chemistry, vol. 13, no. 4, pp. 532-545, 2013.

[149] V. M. Golubovskaya, B. Ho, M. Zheng et al., "Disruption of focal adhesion kinase and p53 interaction with small molecule compound R2 reactivated p53 and blocked tumor growth," BMC Cancer, vol. 13, article no. 342, 2013.

[150] V. M. Golubovskaya, B. Sumbler, B. Ho, M. Yemma, and W. G. Cance, "MiR-138 and MiR-135 directly target focal adhesion kinase, inhibit cell invasion, and increase sensitivity to chemotherapy in cancer cells," Anti-Cancer Agents in Medicinal Chemistry, vol. 14, no. 1, pp. 18-28, 2014.

[151] M. E. Roh, M. Cosgrove, K. Gorski, and I. S. Hitchcock, "Offtargets effects underlie the inhibitory effect of FAK inhibitors on platelet activation: studies using Fak-deficient mice," Journal of Thrombosis and Haemostasis, vol. 11, no. 9, pp. 1776-1778, 2013.

[152] S. N. Hochwald, C. Nyberg, M. Zheng et al., "A novel small molecule inhibitor of FAK decreases growth of human pancreatic cancer," Cell Cycle, vol. 8, no. 15, pp. 2435-2443, 2009. 

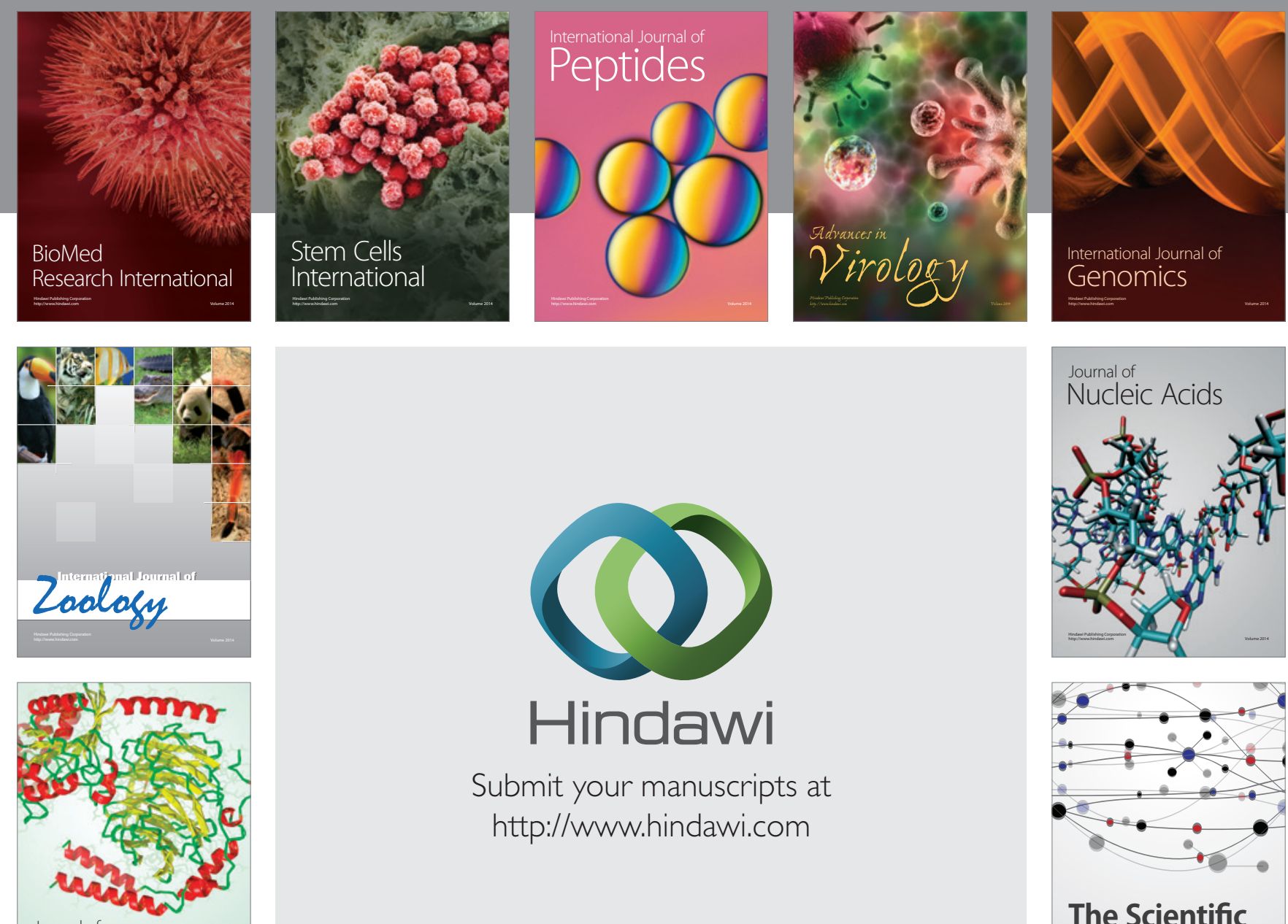

Submit your manuscripts at

http://www.hindawi.com

Journal of
Signal Transduction
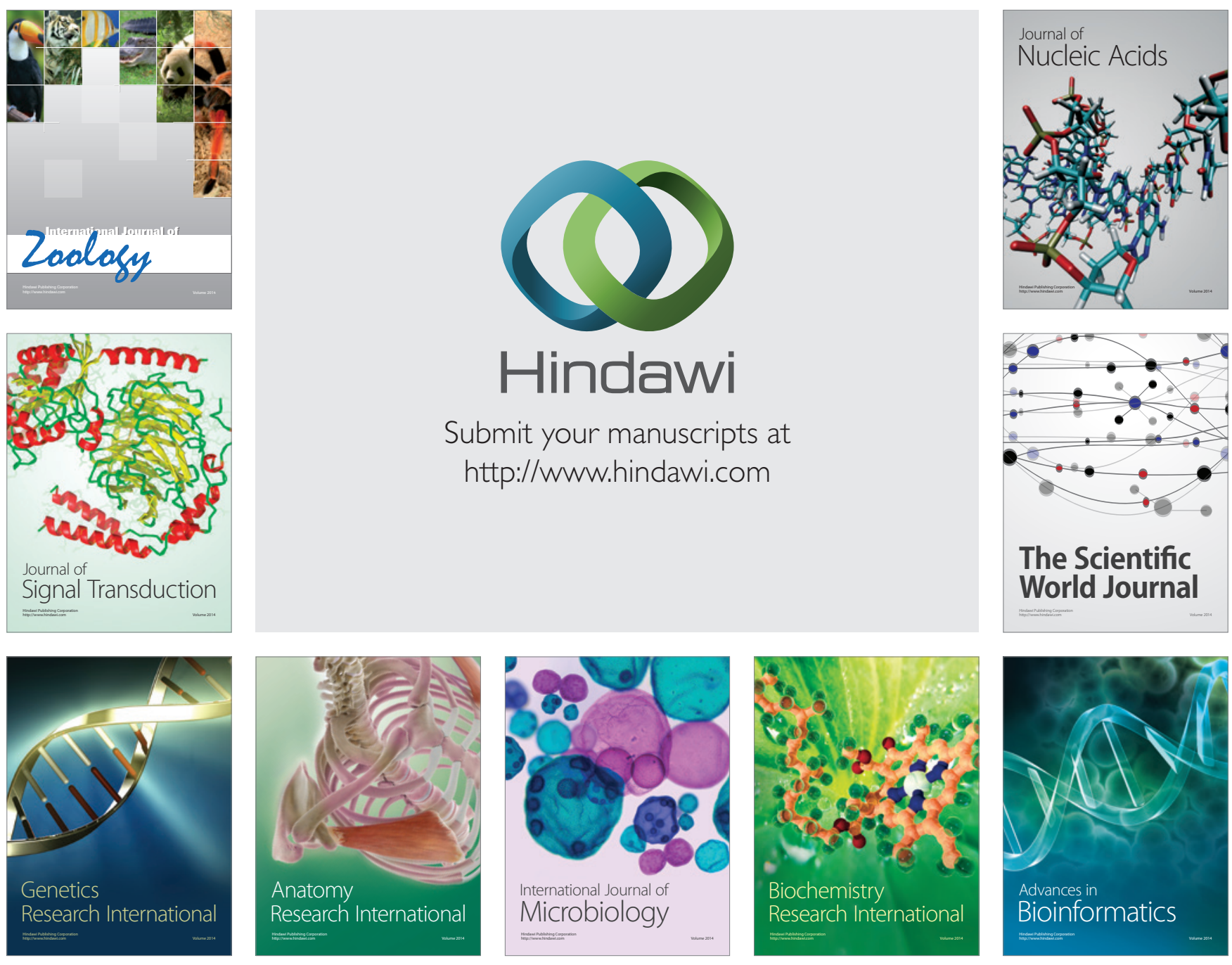

The Scientific World Journal
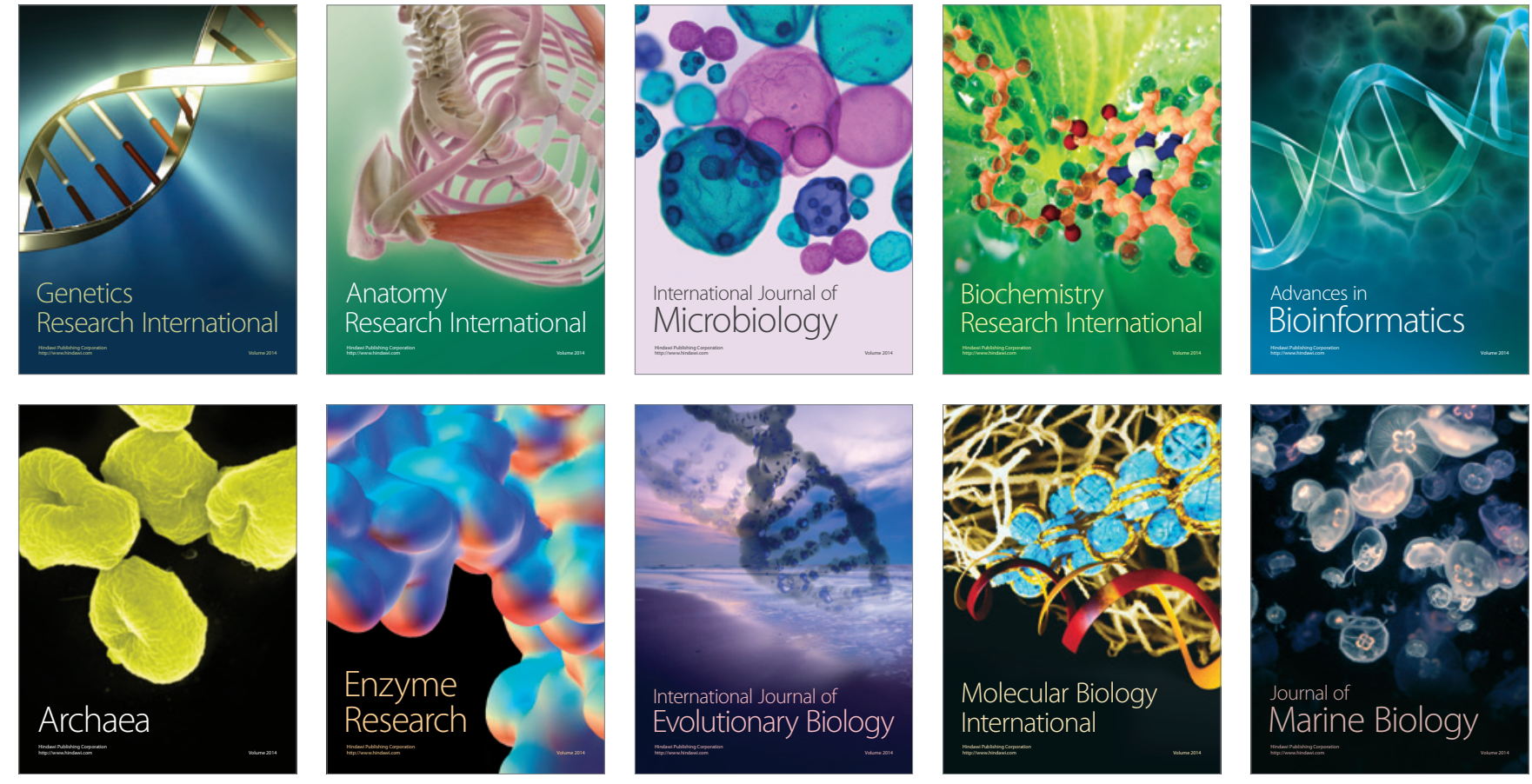